\title{
(อ) OPEN ACCESS \\ Epidemiological methods used in the periodontal health research in military personnel: a systematic review
}

\author{
Millán Bárcena García, J M Cobo Plana, ${ }^{2}$ G Rodríguez Cagiao, ${ }^{3}$ P I Arcos González ${ }^{4}$
}

'Department of Dentistry, Military Army Base 'Conde de Gazola', Ministry of Defense, Ferral del Bernesga, León, Spain ${ }^{2}$ Department of Surgery and Medical and Surgical Specialties, University of Oviedo, Faculty of Medicine and Health Sciences, Oviedo, Asturias, Spain ${ }^{3}$ Department of Dentistry, Military School of Health, Central Defense Academy, Ministry of Defense, Madrid, Spain

${ }^{4}$ Department of Medicine, University of Oviedo, Faculty of Medicine and Health Sciences, Oviedo, Asturias, Spain

\section{Correspondence to}

Capt Millán Bárcena García, Department of Dentistry, Military Army Base 'Conde de Gazola', Ministry of Defense, 24260, Ferral del Bernesga, León, Spain; millanbg@hotmail. com

Received 12 August 2021 Accepted 15 November 2021

\begin{abstract}
Introduction Periodontal disease is a prevalent pathology in military personnel worldwide. The objective is to analyse the methodological features of periodontal health research performed in military personnel in their home countries.
\end{abstract}

Methods A PRISMA systematic review of literature was carried out in PubMed, EMBASE and Web of Science databases on military periodontal health studies. Study design type, language, publication date, year, country, size and sample selection, age, sex, military, diagnostic procedure, examiners, periodontal, gingival and oral hygiene index were extracted.

Results Eighty-eight out of 5355 studies found were selected, published between 1921 and 2020, with samples ranging from 52 to 16869 individuals, generally not randomised, and consisting mainly of men with a mean age of 25 years. Predominant studies were crosssectional descriptive studies, carried out in the Army, on American military personnel, and in the English language. Most of the studies used the WHO periodontal probe handled by two or more examiners. The Löe and Silness gingival index and the Silness and Löe plaque index were the most used indexes to assess gingival condition and oral hygiene, respectively. Community Periodontal Index of Treatment Needs was the most widely used periodontal index.

Conclusions Research on periodontal health carried out in military populations from the 1920s to the present has been performed from an almost exclusively descriptive approach. Issues such as the characteristics and representativeness of the samples, the epidemiological design and the different gingival-periodontal indexes used may limit the comparability of the study results.

\section{INTRODUCTION}

Periodontal disease is a common oral pathology with a global distribution and has been defined as 'any disorder of the tissues surrounding and supporting the teeth, commonly referred to as bacteria-induced inflammatory disorders of the periodontium'. ${ }^{1}$

The prevalence of periodontal disease is assessed through epidemiological indexes that measure the periodontal health of the population, which also allow formulation of strategies for the prevention, control and reduction of the disease. The following three types of indexes are the most used in periodontology: oral hygiene indexes (estimates biofilm and dental calculus); gingival indexes (evaluates gum inflammation) and periodontal indexes (detect periodontal disease by measuring several

\section{Key messages}

- Periodontal disease is a common chronic noncommunicable pathology and is one of the main causes of tooth loss.

- The periodontal health studies conducted are mainly observational and cross-sectional, in non-randomised samples of highly variable size and in young men.

- The studies mainly used the WHO probe, Community Periodontal Index of Treatment Needs, Löe and Silness gingival index and Silness and Löe plaque index.

- The heterogeneity of the epidemiological design and variability in the measurement of periodontal health hinder the comparability and representativeness of the results.

parameters, such as probing depth and clinical attachment level, which are the most important clinical indicators used).

In military groups, gingival-periodontal pathologies are one of the main causes of oral morbidity after dental caries, both in their own countries and in deployments abroad. ${ }^{2-4}$ At this second geographical context, having good periodontal health in the operational areas is essential, as periodontal conditions may result in temporary discharge from duty, compromising the operability of military units. An example of this situation has been the necrotising periodontal disease ${ }^{5}$ identified during the First World War as 'trench mouth or Vincent's stomatitis', which originated, among other factors, because of the stress to which the military personnel were subjected, which altered their immune response and predisposed them to this disease.

Prevention is an essential pillar that contributes to reducing the number of urgent periodontal interventions in military missions abroad. To prevent the exacerbation of gingivitis or periodontitis after deployment from a non-battle environment to a leading situation, it is necessary to study the periodontal health of the military personnel beforehand using an appropriate methodology, as well as encourage oral health promotion and care in national territory. The efforts should focus on early diagnosis of gingival-periodontal pathologies and encouraging awareness regarding the importance of oral hygiene among military personnel. This includes planning and implementing a preventive 
and curative periodontal health policy adapted to the military environment in home countries.

There are almost no published reviews on the methodology used in the military periodontal health studies. Therefore, the objective of this study is to identify and analyse the methods used for periodontal research conducted at military facilities in their respective national territories, specifically in terms of type of study design, sample selection and size, diagnostic procedure, evaluation indexes used and implementation of the study. To identify the problems related to the methodological design of the periodontal research could ultimately help to improve military periodontal health.

\section{METHODS}

A systematic review of the published scientific literature was conducted following the PRISMA guidelines (Preferred Reporting Items for Systematic reviews and Meta-Analyses). ${ }^{6}$ The search was performed on 31 December 2020, using the inclusion criteria of periodontal health studies performed in a military population on national territory, regardless of the type of study, language or date of publication.

The following studies were excluded: (a) studies on the oral health of military personnel that did not include the periodontal health aspect; (b) those referring only to periodontal emergencies or acute and rapidly progressive periodontal disorders; (c) those conducted in the area of operations because of their unstable context (stress, poor hygiene, increased tobacco consumption), which may influence an adequate diagnosis and (d) those whose abstract was not available.

PubMed, Embase and Web of Science search engines (including Scielo and Medline) were used. In the Pubmed search, the following $\mathrm{MeSH}$ terms were used: periodontal diseases, periodontitis, periodontal pocket, periodontal attachment loss, gingivitis, gingival haemorrhage, periodontal index, oral hygiene index, dental plaque index, dental plaque, military personnel, military health, military health services, hospitals, military and military dentistry. A complementary search was also performed in PubMed, Embase and Web of Science with the following keywords: military, conscript, soldier, Armed Forces, Army, Navy, Air Force, periodontal, gingival and dental plaque.

Information on year, country, sample size and selection, age, sex, military, design; periodontal, gingival and oral hygiene indexes; diagnostic procedure, examiners and language were extracted from each study. The mean was used as the parameter of central tendency; the SE of mean (SEM) and CI were used as the dispersion parameters.

\section{RESULTS}

The initial search identified 2788 studies in Embase, 1907 in PubMed and 640 in Web of Science. After reviewing the abstracts, and full papers where necessary, 88 studies were found that met the required inclusion criteria to be incorporated into the systematic review. ${ }^{2-93}$ Figure 1 represents PRISMA flow diagram and Table 1 summarises the studies in which the authors provided relevant information regarding the epidemiological design, sample, person variables, indexes used and diagnostic procedures.

\section{Study design, year and context}

The primary epidemiological design used (89.8\%) was the observational, descriptive and cross-sectional study, where only six $(6.8 \%)$ were longitudinal intervention studies and three $(3.4 \%)$ were case-control.

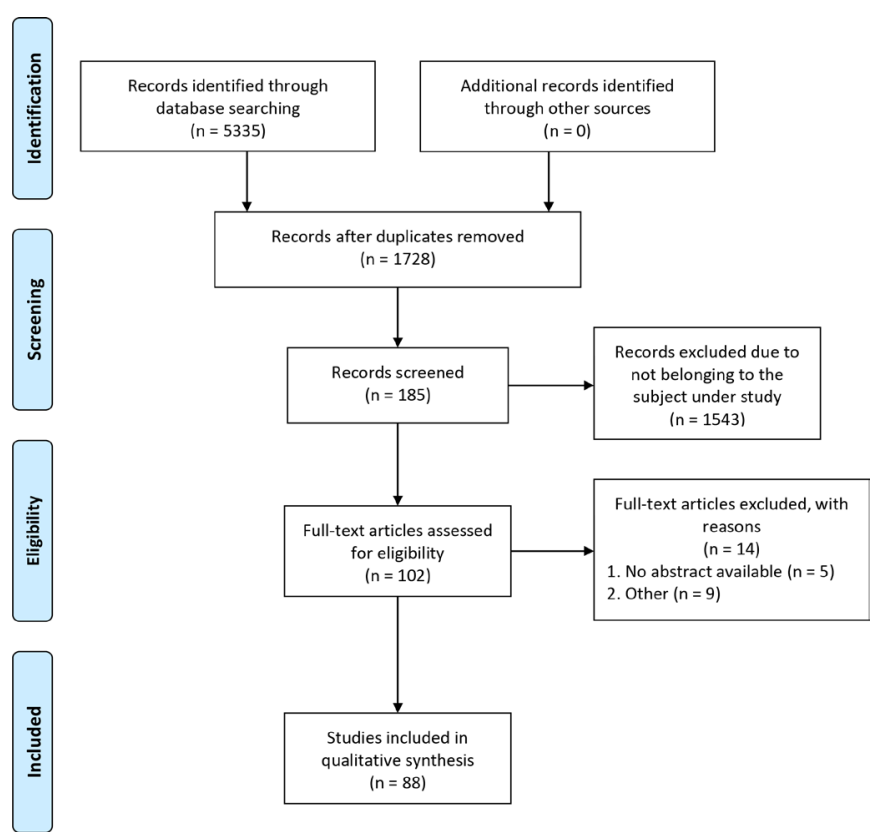

Figure 1 PRISMA diagram illustrating the literature search and identification process. PRISMA, Preferred Reporting Items for Systematic Reviews and Meta-Analyses.

The first of the 88 analysed studies was published in 1921 and the last one in 2020; only six (6.9\%) were published before 1964 and the majority were published during the first decade of the 21st century (Figure 2), especially between 2008 and 2010. Most of the studies (20.5\%) were conducted on American military personnel, followed by Italian and Swiss personnel $(8 \%)$. The largest number of the studies (73.9\%) were published in English, 6.8\% were in Italian and German, 5.7\% in Spanish, 2.3\% in Danish and Russian and 1.1\% in French and Polish.

A total of $35.2 \%$ of the studies were conducted in military personnel of the Army, $12.5 \%$ in the Navy, $12.5 \%$ in the Air Force, $23.9 \%$ in joint military personnel of the Armed Forces, and $15.9 \%$ did not mention the army of origin of the sample studied. Of the 11 studies conducted in the Navy, 54.5\% were carried out in the USA.

\section{Sample features and inference}

The reviewed studies were conducted in samples with a wide size range, from 52 to 16869 individuals, and an average size of 1635 individuals $(S E M=304.8)$. However, due to the wide sample size range, this average value has limited relevance as a parameter of central tendency. Of these, $27.3 \%$ had samples of 100-300 subjects. Of the 55 studies that indicated the sample selection procedure, only $34.5 \%$ had used a random method, and the remaining included convenience samples chosen because of different reasons, including volunteers, periodic dental examination, military service recruits, academy cadets and so on. In the studies conducted in the USA, this percentage was higher (44.4\%).

A limitation found in the studies is the absence of parameters of statistical inference. Only 23 studies (26.1\%) included the CI in some of the variables to measure periodontitis, $16(18.2 \%)$ for gingivitis and $19(21.6 \%)$ for oral hygiene. The statistical inference to the population of other parameters, such as presence of dental caries, was only reported in 20 studies (22.7\%) and in 18 $(20.5 \%)$ for age. 


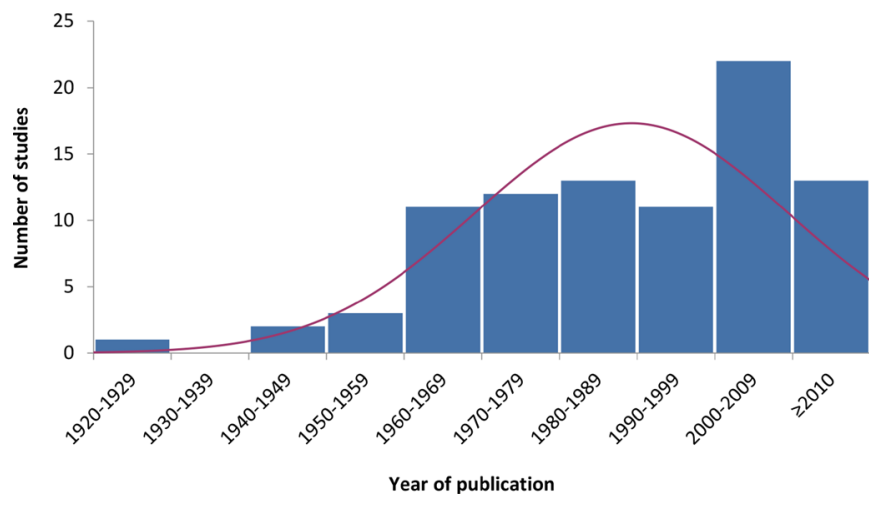

Figure 2 Distribution of the studies by decade of publication.

\section{Person variables}

In the 49 studies that specified the mean age of the participants, the range was $13-84$ years with a mean age of 24.5 years $(\mathrm{SEM}=0.9)$. The reason data were reported on adolescent patients is because in one of the selected studies they belonged to the National Cadet Corps in India and on elderly patients because some studies also included retired military personnel. Only men were included in 50\% of the studies and $27.3 \%$ included military personnel of both sexes. Only one study (1.1\%) was conducted in women and 19 studies (21.6\%) did not specify the sex of the participants in the selected sample.

\section{Indexes and implementation procedures}

The studies used various clinical parameters to assess periodontal disease, which are described below. Community Periodontal Index of Treatment Needs (CPITN) was the most used index (19 studies, 21.6\%), followed by Russell index in 9 studies (10.2\%) and Community Periodontal Index (CPI) and Periodontal Screening and Recording in 5 (5.7\%). Only 2 studies (2.3\%) used Ramfjörd Periodontal Disease Index and Navy Periodontal Disease Index and 14 studies (15.9\%) used other parameters.

In $39.8 \%$ of the studies, gingival status was assessed, the most frequent index being Löe and Silness gingival index in nine studies (10.2\%); gingival bleeding index (BOP) in seven studies (8\%) and sulcus bleeding index by Mühlemann and Son and Papillary-Marginal-Attachment index by Schour and Massler, both in five studies each (5.7\%).

Biofilm calculation was estimated in $35.2 \%$ of the studies, the most frequent indexes being Silness and Löe plaque index, in eight studies (9.1\%), and Greene and Vermillion oral hygiene index and the simplified oral hygiene index by Greene and Vermillion (OHI-S), both in seven studies each (8\%).

In 28 studies (31.8\%), the examination was performed by one examiner and in another $37(42 \%)$, by two or more examiners. Of the 47 studies (53.4\%) that reported using a periodontal probe in their measurements, the most widely used was the WHO probe in $22(25 \%)$ of them. In another 22 studies $(25 \%)$, different first-generation probes were used, and only $2(2.3 \%)$ used a second-generation probe and $1(1.1 \%)$ used a thirdgeneration probe.

\section{DISCUSSION}

The problem of choosing an appropriate index to measure periodontal status

Until 2017, there was not a clear consensus about the clinical criteria to be used in defining periodontal disease. ${ }^{94}$ Researchers have used different epidemiological study designs and 
heterogeneous implementation methods. This variety of research methods, which involves the three types of indexes most used in periodontics (periodontal, gingival and oral hygiene indexes), is a relevant issue because it limits the comparability of the study results and leads to undesirable confusion in the estimation of prevalence and severity of the disease. ${ }^{95}$

Regarding periodontal indexes, the first used for epidemiological purposes was the Russell periodontal index but WHO has been using CPITN since 1987. This index was designed primarily to assess the needs for periodontal treatment of large populations rather than their periodontal status. In 1997, the CPI was introduced but only a few countries record this index due to the difficulty in its correct execution and the time involved. ${ }^{96}$ Torres et al found that both CPITN and CPI have limitations to adequately assess the prevalence of periodontal disease as they are based on a hierarchical criterion of its progression. ${ }^{97}$

In 2013, WHO introduced the modified CPI to reduce the weaknesses of the CPI and increase its simplicity and reproducibility. In this case, as with the indexes that measure caries, such as the Klein and Palmer Decayed-Missing-Filled Teeth index, ${ }^{98}$ all teeth are periodontally scanned, detailing in each tooth, the presence or absence of bleeding and periodontal pockets. This index also records attachment loss.

Dissimilar cut-off values to measuring periodontal pocket depth and level of clinical attachment to establish the existence of disease have been used. In addition, a non-homogeneous number of locations have been evaluated in each tooth and/or a simplified way of the periodontal examination of all teeth using partial registrations. ${ }^{99}$

In the set of studies analysed, the difficulty of selecting a periodontal index has been mentioned as a main issue. ${ }^{27}$ This problem also affects the use of the bleeding on probing index ${ }^{3456}$ and advocates the need for a more comprehensive periodontal examination. ${ }^{1144688083}$ Covington et al suggested that none of the periodontal indexes used to detect periodontal disease have been universally accepted or used routinely by most researchers. ${ }^{34}$

According to Trombelli et al, gingival indexes are subjective by nature, and researchers have based their index choice on various criteria, of which bleeding on probing is the most objective indicator to assess gingivitis. ${ }^{100}$ This is because quantitative measurement of bleeding is more difficult to analyse than the presence or absence of bleeding after probing. Furthermore, the measurement result could be influenced by the pressure exerted by the examiner, even with a slight probing.

In relation to oral hygiene indexes, their lack of precision, sensitivity and specificity as well as the need to improve intraexaminer and interexaminer concordance to increase reliability in examinations performed at different periods of time within the same centre or in multiple centres have been also mentioned as a limitation by Pretty et al. ${ }^{101}$

Due to the aforementioned differences in research methods and indexes used, it is not easy to compare prevalence and severity of periodontal pathology in military studies. Additionally, it is difficult to compare the results with civilian populations because of the differences in demographic composition, mainly by sex and age structure (the presence of female military staff is still low in armies and the mean age of military personnel is also relatively lower than the civilian population of the same geographic areas). Age is also different in the military studies reviewed (the samples in several studies are composed by conscripts and in other studies by professional military staff or veterans with different age ranges).
Issues regarding epidemiological design and implementation The mainly descriptive epidemiological designs ${ }^{30} 46$ used have been pointed out as a research limitation by several authors, ${ }^{71240}$ as well as the scarce presence of longitudinal designs, ${ }^{9}$ cohorts ${ }^{42}$ or studies assessing the level of exposure to risk factors.

There is a reduced representativeness of the study samples used $^{4880}$ due to specific issues like the samples size, ${ }^{11} 165458$ nonrandom selection, ${ }^{25457383}$ lack of responses, ${ }^{60}$ selection biases ${ }^{103367}$ and under-representation of variables ${ }^{27} 6064708592$ which reduce data extrapolation. ${ }^{18} 343840447077$ A limitation found in several studies is the absence of statistical inference parameters. The need to extend or complement the statistical analysis of the results to improve the usefulness of the study is another issue mentioned ${ }^{82}$ as well as a more extensive analysis of potential biases in order to optimise the validity of the results. ${ }^{363958626475}$

As a determining factor for the comparability of the results, certain characteristics of the type of epidemiological design used in the studies have been mentioned, ${ }^{65}$ including those related to the procedures and implementation of the study ${ }^{17} 33718890$ and/ or methods applied 44547292 that establish the existence of periodontal disease. ${ }^{25169}$

We need to agree on a standardised methodology for use in future studies evaluating the periodontal health of military personnel. In this sense, our proposal is to use the modified CPI and periodontal attachment level to analyse the periodontal condition as well as bleeding on probing to evaluate gingivitis, since both are objective and easy to apply in population studies. On the other hand, it is more difficult to propose an oral hygiene index among those that currently exist since none of them is universally applicable. However, the O'Leary index could be proposed to estimate dental biofilm due to its reliability and simplicity in population studies. Although an electronic probe as a measuring instrument could guarantee accuracy in measurements, its availability is not widespread. For this reason, the WHO manual probe could be the chosen alternative for conducting military epidemiological studies due to its wide availability and ease of use.

\section{Limitations}

Several limitations are recognised in the writing of this paper. We have selected studies conducted only in the home countries of the armies excluding those performed in deployment abroad as well as studies carried out only in active-duty military personnel. Furthermore, having included studies since 1921, the quality of the information provided by the authors can be variable over this long period of time.

\section{CONCLUSION}

Research on periodontal health carried out in military populations from the 1920s to the present has been performed from an almost exclusively descriptive approach and conducted mainly through cross-sectional observational studies. To assess periodontal status, the authors essentially used the WHO probe and three indexes: CPITN periodontal index and the gingival and plaque indexes, both developed by Silness and Löe. The limitations found related to the epidemiological design and/or its implementation may reduce the representativeness of the results and their comparability.

Acknowledgements We would like to thank Manuel Fernández Gómez, from the Health Sciences Library of the University of Oviedo, for his invaluable help in the bibliographic search.

Contributors MBG, JMCP, GRC and PIAG are responsible for the general content of the manuscript. All contributed equally to the design, implementation of the research, analysis of results, and writing of the manuscript. The author who will act as overall guarantor is Millán Bárcena García (MBG). 
Funding The authors have not declared a specific grant for this research from any funding agency in the public, commercial or not-for-profit sectors.

Competing interests None declared.

Patient consent for publication Not applicable.

Provenance and peer review Not commissioned; externally peer reviewed.

Data availability statement Data are available on reasonable request.

Open access This is an open access article distributed in accordance with the Creative Commons Attribution Non Commercial (CC BY-NC 4.0) license, which permits others to distribute, remix, adapt, build upon this work non-commercially, and license their derivative works on different terms, provided the original work is properly cited, appropriate credit is given, any changes made indicated, and the use is non-commercial. See: http://creativecommons.org/licenses/by-nc/4.0/.

\section{REFERENCES}

1 Teufer B, Sommer I, Nussbaumer-Streit B, et al. Screening for periodontal diseases by non-dental health professionals: a protocol for a systematic review and overview of reviews. Syst Rev 2019;8:1-12.

2 Bárcena García M, Cobo Plana JM, Arcos González PI. Prevalence and severity of periodontal disease among Spanish military personnel. BMJ Mil Health 2020:bmjmilitary-2020-001419.

3 Lloro V, Lozano-de Luaces V, Lloro I, et al. The incidence of dental needs during isolated missions compared to non-isolated missions: a systematic review and implications for future prevention strategies. Mil Med 2019;184:e148-55.

4 Combes J, Pepper T, Bryce G, et al. Dental care provision to UK military personnel serving on Operation Herrick in Afghanistan. Part 2: aetiology and management. $\mathrm{Br}$ Dent J 2019;226:50-4.

5 Dufty JR. Report for the pathological committee of the war office of an inquiry into gingivitis and Vincent's disease occurring in the Army. BMJ Mil Health 2014:160:i7-8

6 Page MJ, McKenzie JE, Bossuyt PM, et al. The PRISMA 2020 statement: an updated guideline for reporting systematic reviews. BMJ 2021:372:n71.

7 Schindler DK, Lopez Mitnik GV, Soliván-Ortiz AM. Oral health status among adults with and without prior active duty service in the U.S. Armed Forces, NHANES 20112014. Mil Med 2020:3.

8 Azevedo L, Martins D, Fialho J, et al. Oral health behaviors and dental caries in a sample of Portuguese militaries. j.rpemd 2018;59:18-23.

9 Khalilazar L, Khoshdel AR. Oral health profile in Iranian Armed Force: focusing on prevention strategies. J Arch Mil Med 2016;4:e39275.

10 Thankappan P, Kaushik S, Gupta S, et al. Periodontal diseases in military aviation crew: a pilot study in armed forces. J Int Clin Dent Res Organ 2015;7:116-21.

11 Kovacević V, Milosavljević M, Rancić N, et al. Assessment of the periodontal health and community periodontal index in the Army of Serbia. Vojnosanit Pregl 2015;72:953-60.

12 Tanner T, Päkkilä J, Karjalainen K, et al. Smoking, alcohol use, socioeconomic background and oral health among young Finnish adults. Community Dent Oral Epidemiol 2015;43:406-14.

13 Simakova TG, Kasaikina VV, Minaev SS. [Characteristics of dental health personnel]. Zdorov'e naseleniya i sreda obitaniya 2014;3:19-20.

14 Kurov IA, Skalnaya MG. [The study of changes of local immunity of the oral cavity and periodontal indices of conscripts]. J Restor Med 2013;6:63-7.

15 Álvarez CL, Rico V, Gómez JC. [Prevalence, severity and periodontal treatment needs of periodontal disease in air defense artillery branch \# 2 Nueva Granada]. Ustasalud 2013;12:11-19.

16 Leiendecker TM, Martin G, Moss DL. 2008 department of defense (DOD) recruit oral health survey. Mil Med 2011:176:1-44.

17 Ziebolz D, Szabadi I, Rinke S, et al. Initial periodontal screening and radiographic findings -a comparison of two methods to evaluate the periodontal situation. $B M C$ Oral Health 2011:11:13.

18 Zajc I, Brajdić D, Biočić J, et al. The effect of tobacco use on oral health and dental readiness in the Croatian Army. J Addict Dis 2011;30:159-68.

19 Singh A. Oral health knowledge, attitude and practice among NCC Navy Cadets and their correlation with oral hygiene in South India. Oral Health Prev Dent 2009; $7: 363-7$

20 Sutthavong S, Cae-Ngow S, Rangsin R. Oral health survey of military personnel in the Phramongkutklao Hospital, Thailand. J Med Assoc Thai 2009;92 Suppl 1:S84-90.

21 Villota DD, Cardona M, Vivas J. [Prevalence and factors related to tooth decay and periodontal disease in cadets of the Military Aviation School]. J Odontológico Col 2009;2:55-60

22 Fraczak B, Rawski P, Dembowska E. [Dental status, parodontium condition and occurrence of malocclusions in conscripts from the West Pomeranian Voivodship, Poland]. Ann Acad Med Stetin 2008:54:63-8.

23 Ziebolz D, Schwerdtfeger B, Brunner E, et al. [Oral health in young adults in Germany--a comparison between women and men of the German army]. Schweiz Monatsschr Zahnmed 2008;118:944-50.
24 Doncel C, Castillo A. [Determination of the need of periodontal treatment in the young from a military schooll]. Rev Cub Med Mil 2008;37.

25 Parwez M, Babar Z, Akhtar F. Frequency of chronic periodontitis in a cross section of PAK Army personnel. Pak Armed Forces Med J 2008;58:185-8.

26 Suman M, Spalj S, Plancak D, et al. The influence of war on the oral health of professional soldiers. Int Dent J 2008:58:71-4.

27 Vered Y, Livny A, Zini A, et al. Periodontal health status and smoking among young adults. J Clin Periodontol 2008:35:768-72.

28 Mombiedro Sandoval R, Llena Puy R. Periodontal status and treatment needs among Spanish military personnel. Med Oral Patol Oral Cir Bucal 2008;13:464-9.

29 Röthlisberger B, Kuonen P, Salvi GE, et al. Periodontal conditions in Swiss army recruits: a comparative study between the years 1985, 1996 and 2006. J Clin Periodontol 2007:34:860-6.

30 Diefenderfer KE, Ahlf RL, Simecek JW, et al. Periodontal health status in a cohort of young US Navy personnel. J Public Health Dent 2007:67:49-54.

31 Skec V, Macan JS, Susac M, et al. Influence of oral hygiene on oral health of recruits and professionals in the Croatian Army. Mil Med 2006;171:1006-9.

32 Otero J, Proaño D. [Prevalence of periodontal diseases, risk factors, and treatment needs among male personnel on military service in Lima in the year 2000]. Rev Estomatológica Hered 2005;15:11-17.

33 Senna A, Campus G, Gagliani M, et al. Socio-Economic influence on caries experience and CPITN values among a group of Italian call-up soldiers and cadets. Oral Health Prev Dent 2005;3:39-46.

34 Covington LL, Breault LG, Hokett SD. The application of Periodontal Screening and Recording (PSR) in a military population. J Contemp Dent Pract 2003;4:36-51.

35 Vered Y, Sgan-Cohen HD. Self - perceived and clinically diagnosed dental and periodontal health status among young adults and their implications for epidemiological surveys. BMC Oral Health 2003;3:3:3.

36 Horev T, Katz J, Almog D, et al. Oral health disparities between ranks in a military environment: Israel Defense Force as a model. Mil Med 2003:168:326-9.

37 Ahuja A, Darekar HS. Community dentistry in Armed Forces. Med J Armed Forces India 2003:59:18-20.

38 Griffiths GS, Duffy S, Eaton KA, et al. Prevalence and extent of lifetime cumulative attachment loss (LCAL) at different thresholds and associations with clinical variables: changes in a population of young male military recruits over 3 years. J Clin Periodontol 2001;28:961-9.

39 Katz J, Peretz B, Sgan-Cohen HD, et al. Periodontal status by CPITN, and associated variables in an Israeli permanent force military population. J Clin Periodontol 2000;27:319-24.

40 Machuca G, Rosales I, Lacalle JR, et al. Effect of cigarette smoking on periodontal status of healthy young adults. J Periodonto/ 2000;71:73-8.

41 Leiendecker T, York A, Poindexter F. Periodontal screening and recording findings of active duty US military. J Dent Res 1997;76:2694

42 Ankkuriniemi O, Ainamo J. Dental health and dental treatment needs among recruits of the Finnish Defence Forces, 1919-91. Acta Odontol Scand 1997;55:192-7.

43 Horev T, Zilburg I, Sgancohen HD. Periodontal profile of 20-21 year-old Israeli soldiers. J Dent Res 1995;74:960

44 Querna JC, Rossmann JA, Kerns DG. Prevalence of periodontal disease in an active duty military population as indicated by an experimental periodontal index. Mil Med 1994:159:233-6.

45 Joss A, Weber HP, Gerber C, et al. Periodontal conditions in Swiss Army recruits. Schweiz Monatsschr Zahnmed 1992;102:541-8.

46 Horning GM, Hatch CL, Cohen ME. Risk indicators for periodontitis in a military treatment population. J Periodontol 1992:63:297-302

47 Menghini GD, Marthaler TM, Steiner M, et al. [Caries prevalence and gingival inflammation in recruits in 1985: the influence of prevention]. Schweiz Monatsschr Zahnmed 1991:101:1119-26.

48 Polastri F, Cerato E, Gallesio C, et al. [The oral health status in a sample of recruits form different regions of Italy]. Minerva Stomatol 1991:40:397-403.

49 Stramezzi AM, Puleo A, Barbini P. [Epidemiology of caries and periodontal disease. Survey of 5,000 recruits]. Dent Cadmos 1990:58:64-75.

50 Arthur JS, Simecek JW, Rodden JW. Periodontal treatment needs survey of navy and marine reserve personnel. J Dent Res 1990;69:134

51 Horning GM, Hatch CL, Lutskus J. The prevalence of periodontitis in a military treatment population. J Am Dent Assoc 1990;121:616-22.

52 Gaare D, Joelimar FA, Ouderaa FV, et al. A cross-sectional study of DMFT and CPITN scores in a group of Indonesian soldiers. Scand I Dent Res 1989;97:20-4

53 D'Aloya U, Facchini A, Franchi M, et al. [Periodontal status of a military group. Epidemiological considerations]. Dent Cadmos 1989;57:78-84.

54 Petersson LG, Jönsson G, Stadler LE, et al. Oral status and estimated treatment need in Swedish air force conscripts. Swed Dent J 1989;13:69-76.

55 Henne HA, Flores-de-Jacoby L, Zafiropoulos GG. [Epidemiological examination of the periodontal condition of West German soldiers by the means of the community periodontal index of treatment needs (CPITN)]. Dtsch Zahnarztl Z 1988;43:696-700

56 Sasaki Y, Takahashi Y, Arita K, et al. Assessment of periodontal treatment needs in Japan Maritime Self Defense Force by CPITN. Bull Tokyo Dent Coll 1988;29:21-5.

57 Shulman JD, Guerin RD, Rozier RG. Prevalence of periodontal pockets in US Army reserve components. J Dent Res 1987;66:256 
58 Miotti F, Passi P, De Nart E. [Epidemiological study of dento-periodontal conditions in a group of recruits from various Italian regions]. G Stomatol Ortognatodonzia 1987;6:40-4.

59 Musajo F, Passi P, Curra G. [Epidemiologic dento-periodontal survey of a group of military recruits in various conditions of employment]. Parodontol Stomatol $1985 ; 24: 93-8$

60 Moock P. [An orodental epidemiologic study in a population of flight personnel on an air base]. Inf Dent 1984:66:1847-71.

61 Salvato A, Landenna P, Loiaconi G, et al. [Survey of dental caries and periodontal disease in recruits in Lombardy (I)]. Prev Stomatol 1982;8:13-17.

62 Anagnou-Vareltzides A, Tsami A, Zervogianes D, et al. Oral hygiene and gingival health in Greek airforce cadet candidates. Community Dent Oral Epidemiol 1982;10:60-5.

63 Wennström JL, Carlson OG, Liljequist C. Periodontal disease in military aircrew members: a clinical and radiographical study. Aviat Space Environ Med 1981;52:354-7.

64 Preber H, Kant T, Bergström J. Cigarette smoking, oral hygiene and periodontal health in Swedish army conscripts. J Clin Periodontol 1980;7:106-13.

65 Christen AG, Park PR, Graves RC, et al. United States Air Force survey of dental needs, 1977: methodology and summary of findings. J Am Dent Assoc 1979;98:726-30.

66 Petersen PE, Stoltze K. [Caries incidence and gingival status in 686 Navy sailors]. Tandlaegebladet 1979;83:607-14.

67 Lang NP, Engelmayer H. [Periodontal status in a group of Swiss soldiers age 28-32 years]. Schweiz Monatsschr Zahnmed 1979;89:1095-102.

68 Wirthlin MR, Keene HJ, Shklair IL. Gingivitis, bacterial plaque, and Streptococcus mutans in naval recruits from Saudi Arabia. J Periodontol 1977;48:209-11.

69 Hancock EB, Wirthlin MR. An evaluation of the Navy Periodontal Screening Examination. J Periodontol 1977;48:63-6.

70 Bayirli GS, Curilović Z. Periodontal condition in Turkish recruits. Community Dent Oral Epidemiol 1976;4:25-9.

71 Mörmann W, Regolati B, Lutz F, et al. The gingivitis fluorescein test in recruits. Helv Odontol Acta 1975;19:27-30.

72 Germann MA, Curilović Z, Saxer UP. [Periodontal condition of a group of Swiss Army recruits]. Schweiz Monatsschr Zahnmed 1973;83:1220-9.

73 Bay I. [Oral hygiene and periodontal condition in a group of young Danish conscripts]. Tandlaegebladet 1972;76:1176-86.

74 Curilović Z, Renggli HH, Saxer UP. [The condition of the periodontium in a group of Swiss recruits]. Schweiz Monatsschr Zahnmed 1972:82:437-51.

75 Ainamo J. Awareness of the presence of dental caries and gingival inflammation in young adult males. Acta Odontol Scand 1972;30:615-9.

76 Kristoffersen T. Periodontal conditions in Norwegian soldiers--an epidemiological and experimental study. Scand J Dent Res 1970;78:34-53.

77 Dale JW. Prevalence of dental caries and periodontal disease in military personnel. Aust Dent J 1969;14:30-6

78 Borghelli RF, Andrade JH, Vigna A. Preliminary observation of oral hygiene and periodontal condition in soldiers. J Dent Res Supplement 1969;48:1070-1.

79 Borghelli RF, Barocela RC, Bernini JM. [Prevalence of inflammatory gingival lesions in soldiers]. Rev Sanid Milit Argent 1969;68:36-42.
80 Naylor MN, Sharpe GD, Stacey CT. Gingival health in Polaris and conventional submarines. J R Nav Med Serv 1969:55:224-8.

81 Kaslick RS, Chasens Al. Periodontosis with periodontitis: a study involving young adult males. I. Review of the literature and incidence in a military population. Oral Surg Oral Med Oral Pathol 1968;25:305-26.

82 Lightner LM, O'Leary TJ, Drake RB, et al. The periodontal status of incoming Air Force Academy cadets. J Am Dent Assoc 1967;75:111-7.

83 Milne AM. Gingival bleeding in 848 Army recruits. An assessment. Br Dent $J$ $1967 ; 122: 111-2$

84 Shiller WR. Periodontal health of submarine school candidates: a correlative analysis. J Periodontol 1966:37:224-9.

85 Burnett GW, Moreira BJ, Imm BC, et al. Oral health status of military personnel in the Federation of Malaya, 1962. Mil Med 1965;130:68-72.

86 Brandtzaeg P, Jamison HC. A study of periodontal health and oral hygiene in Norwegian Army recruits. J Periodontol 1964;35:302-7.

87 Burnett GW, Chao C. Oral health status of the Armed Forces of the Republic of China. Mil Med 1964;129:848-54.

88 Stein LM, Carter WJ, Englander HR. Caries symmetry and gingivitis in military women; a study of 243 waves. U S Armed Forces Med J 1955;6:204-9.

89 Massler M, Ludwick W, Schour I. Dental caries and gingivitis in males 17 to 20 years old (at the great lakes naval training center). J Dent Res 1952;31:195-9.

90 Pindborg JJ. Influence of service in Armed Forces on incidence of gingivitis. J Am Dent Assoc 1951;42:517-22.

91 Light AE. Bleeding gums in Army personnel. Bull U S Army Med Dep 1947;7:789-94.

92 Smart GA. Incidence of gingivitis in the Royal Air force. BMJ 1944;2:242-4.

93 Watts RC, Mohamed SG. The incidence of gingivitis among the Indian troops. Ind Med Gaz 1921:56:97-8.

94 Caton JG, Armitage G, Berglundh T, et al. A new classification scheme for periodontal and peri-implant diseases and conditions - Introduction and key changes from the 1999 classification. J Clin Periodontol 2018;45 Suppl 20:S1-8.

95 Savage A, Eaton KA, Moles DR, et al. A systematic review of definitions of periodontitis and methods that have been used to identify this disease. J Clin Periodontol 2009:36:458-67.

96 Petersen PE, Ogawa H. The global burden of periodontal disease: towards integration with chronic disease prevention and control. Periodontol 2000 2012;60:15-39.

97 Torres F, Ríos J, Velasco E. [Periodontal evaluation in integrated dental practice]. Av Periodoncia 1994:6:119-26.

98 Klein H, Palmer CE, Knutson JW. Studies on dental caries: I. dental status and dental needs of elementary school children. Public Health Rep 1938;53:751-65.

99 Tran DT, Gay I, Du XL, et al. Assessing periodontitis in populations: a systematic review of the validity of partial-mouth examination protocols. J Clin Periodontol 2013:40:1064-71.

100 Trombelli L, Farina R, Silva CO, et al. Plaque-induced gingivitis: case definition and diagnostic considerations. J Clin Periodontol 2018;45 Suppl 20:S44-67.

101 Pretty IA, Edgar WM, Smith PW, et al. Quantification of dental plaque in the research environment. J Dent 2005;33:193-207. 